\title{
RELATOS DE PESQUISAS \\ GESTÃO DO CONHECIMENTO EM REDES DE RELACIONAMENTO INTEROGANIZACIONAIS NO MERCADO DE JOGOS DE TREINAMENTO CORPORATIVOS: ESTUDO DE CASO
}

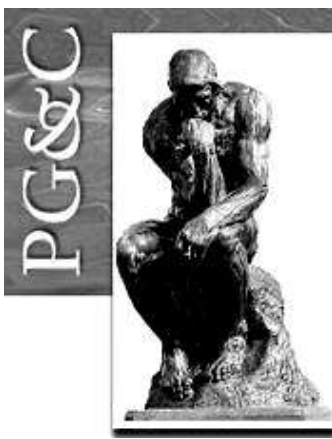

\author{
Roberto Bazanini \\ Doutor em Comunicação e Semiótica pela Pontifícia Universidade Católica \\ de São Paulo, Brasil. Professor da Universidade Paulista, Brasil. \\ E-mail: roberto.bazanini@docente.unip.br \\ Andrea Akemi Oribe Hayashi \\ Mestre em Administração pela Universidade Paulista, Brasil. Bibliotecária \\ Documentalista da Universidade Federal de São Paulo, Brasil. \\ E-mail: andrea hayashi@yahoo.com.br \\ Flávio Romero Macau \\ Doutor em Administração pela Fundação Getúlio Vargas, Brasil. \\ Professor da Edith Cowan University, Austrália. \\ E-mail: f.macau@ecu.edu.au \\ Ricardo Daniel Adra \\ Mestre em Gestión Empresaria pela Universidad Nacional del Comahue, \\ Argentina. Professor da Universidad Nacional del Comahue, Argentina. \\ Email: ricardo.adra@faea.uncoma.edu.ar
}

\begin{abstract}
Resumo
Este estudo possui como objetivo principal descrever a aplicabilidade da ferramenta gestão do conhecimento nas redes de relacionamento das empresas direcionadas para o mercado de jogos de treinamento corporativos. Trata-se de uma pesquisa descritiva, de natureza qualitativa, estudo de caso único e seccional (transversal). A coleta de dados no campo foi realizada por meio de entrevistas semiestruturadas com o gestor e os colaboradores da empresa. Os resultados da pesquisa apontam que a aplicabilidade da gestão do conhecimento nas redes de relacionamento dos jogos de treinamento corporativo como auxílio dos princípios do modelo andragógico proporcionam a empresa em rede acesso maior a recursos tangíveis e intangíveis. Em decorrência, a troca de conhecimento constante favorece a interatividade entre o conhecimento tácito e explícito resultando na oferta de produtos que proporcionam aprendizado atualizado, dinâmico e contínuo para os clientes- usuários dos treinamentos. Com base nesses resultados, conclui-se que os jogos de treinamento corporativos propiciam recursos essenciais para o aprendizado nas organizações e, nessa perspectiva, torna-se relevante a ampliação das discussões dessa temática ao se analisar a efetividade dessas novas práticas nas atividades executivas.
\end{abstract}

Palavras-chave: Redes de relacionamentos interorganizacionais. Gestão do Conhecimento. Vantagem Competitiva. Empresa de Jogos Corporativos.

\section{KNOWLEDGE MANAGEMENT IN THE INTERORGANIZACIONAL RELATIONSHIP NETWORKS OF THE CORPORATE TRAINING GAME MARKET: CASE STUDY}

\begin{abstract}
This study has as main objective to describe the applicability of the knowledge management tool in the relationship networks of companies directed to the corporate training games market. It is a descriptive,
\end{abstract}

Perspectivas em Gestão \& Conhecimento, João Pessoa, v. 10, n. 2, p. 42-66, maio/ago. 2020. DOI: http://dx.doi.org/10.21714/2236-417X2020v10n2p42

http://periodicos.ufpb.br/ojs2/index.php/pgc. ISSN: 2236-417X. Publicação sob Licença (cc) EY-NC-ND 
qualitative research, a single and cross-sectional case study. Data collection in the field was carried out through semi-structured interviews with the company's manager and employees. The results of the research point out that the applicability of knowledge management in the relationship networks of corporate training games as an aid to the principles of the andragogical model provide the networked company with greater access to tangible and intangible resources. As a result, the constant exchange of knowledge favors the interactivity between tacit and explicit knowledge resulting in the offer of products that provide updated, dynamic and continuous learning for customers-users of training. Based on these results, it is concluded that corporate training games provide essential resources for learning in organizations and, in this perspective, it is relevant to expand the discussions on this topic, in order to analyze the effectiveness of these new practices in executive activities.

Keywords: Interorganizational relationship networks. Knowledge management. Competitive advantage. Corporate game company.

\section{INTRODUÇÃO}

Em nossa contemporaneidade o conhecimento organizacional, no contexto das organizações, é considerado um ativo que, embora intangível, resulta em vantagem competitiva. Nas redes de relacionamento essa vantagem é alcançada por meio do aperfeiçoamento contínuo e da inovação do processo produtivo e do produto, sendo que, nesse processo, o conhecimento constitui o recurso organizacional que permite à organização desenvolver atividades de melhoria e inovação (GRANT, 1996; TORUGSA; O'DONOHUE, 2016).

O objetivo principal desse estudo está em descrever a aplicabilidade da ferramenta gestão do conhecimento nas redes de relacionamento das empresas voltadas para o mercado de jogos de treinamento corporativos.

Por intermédio de pesquisa descritiva, de natureza qualitativa, este estudo de caso único e seccional (transversal) busca encontrar respostas para a questão central da pesquisa: como a gestão do conhecimento pode proporcionar vantagem competitiva nas empresas de jogos de treinamento corporativos inseridas em uma rede de relacionamento?

A escolha do mercado de jogos de treinamento corporativos e, particularmente, a interatividade dinâmica que se estabelece entre a Conquistar Jogos Corporativos (CJC) em parceira com a Integração Escola de Negócios (IEN) em rede com a Catalyst Global se justifica por contemplar aspectos de inovação, trabalho em equipe e uso de tecnologias cada vez mais sofisticadas, em perfeita consonância com os requisitos da pós-modernidade. Ou seja, constitui um tipo de produção de conteúdos de educação experiencial em que grupos de executivos devem resolver problemas em um cenário desafiador, no qual os participantes não podem confiar simplesmente em sua experiência anterior para lidar com as novas situações e sim, devem agir com eficácia diante desses desafios.

A afirmação orientadora da pesquisa na perspectiva de (NONAKA; TAKEUCHI, 1997; WONG, et al. 2013) propõe que a GC nas redes de relacionamento dos jogos de treinamento corporativo favorece a integração entre o conhecimento tácito e explícito ao promover diferencial competitivo e criar valor para as empresas em rede em relação à concorrência.

$\mathrm{Na}$ realização desta pesquisa, inicialmente descreve-se as características da GC nas redes e sua aplicabilidade nas empresas de jogos de treinamento corporativos apoiadas no modelo andragógico. A seguir, os procedimentos metodológicos são apresentados, na sequencia, os dados coletados são analisados e discutidos. Finaliza-se o artigo com as considerações finais e recomendações para futuras pesquisas. 


\section{ABORDAGEM TEÓRICA}

Em nossa contemporaneidade, a disponibilidade de informação se tornou muito maior do que a capacidade do ser humano de absorvê-la. Em decorrência, os modelos de aprendizagem corporativa buscam continuamente incorporar técnicas relacionadas à evolução tecnológica, visto que, cada vez mais, as formas tradicionais de comunicação se tornam anacrônicas.

Desse modo, a acirrada competividade no mercado requer que as empresas disponham em seus quadros de profissionais qualificados, dinâmicos e atualizados, E, nesse contexto a GC propicia iniciativas que se apoiam nos desafios impostos por este cenário em que a socialização, o compartilhamento de experiências e o conhecimento formal constituem ativos indispensáveis para o melhor desempenho das organizações (ARGOTE; IGRAM, 2000; HALAWI; ARONSON; MCCARTHY, 2005).

Nesse ambiente competitivo, os jogos corporativos potencializam o emprego da GC ao favorecer o aprendizado coletivo no estabelecimento de melhorias em processos e sistemas, de inovações no modelo de negócios e, especialmente, propiciar uma visão muito mais ampla de toda a competitividade organizacional, incluindo comunicação e inteligência emocional como forma de capacitação de executivos e estudantes (BRANDALIZE, 2018; JUNEJA, 2019).

Em consonância com os pressupostos da andragogia, para o adulto, o conhecimento deve possuir familiaridade com a sua vivência passada (CAVALCANTI; GAYO, 2005; CARVALHO, 2017). Nesse particular, os jogos corporativos propiciam atratividade para atual geração de colaboradores que, de certa forma, cresceu sob influência de diversos tipos de jogos durante a sua infância e adolescência, além do potencial de atratividade dos elementos dos jogos na revolução tecnológica e, em decorrência, também na disseminação do conhecimento.

Ou seja, é possível proporcionar por meio da GC, acompanhado da dinâmica dos jogos corporativos, estratégias inovadoras para criação, coleta, disseminação absorção e integração do conhecimento tácito e explícito no desenvolvimento de habilidades e competências voltadas para os objetivos da empresa.

\subsection{Descrição do objeto de pesquisa}

Jogos corporativos ou team building activities constituem um tipo de educação experiencial em que grupos devem resolver problemas em um novo cenário onde os participantes não podem simplesmente confiar em sua experiência anterior para lidar com as novas situações (WAGNER; CAMPBELL, 1994), promovendo assim o desenvolvimento de equipes que devem se atualizar contínua e criativamente (HATCH; MCCARTHY, 2005).

Comumente, a dinâmica do jogo consiste em uma ampla variedade de desafios planejados que direcionam o interesse dos participantes para o que tem que ser aprendido em um ambiente propício para a construção de uma comunicação eficiente. Esse tipo de ferramenta é utilizado para avaliar o estágio atual do desenvolvimento da equipe, classificar e esclarecer objetivos, aumentar a coesão do grupo e, em consequência, melhorar a produtividade e motivação dos colaboradores (FORSYTH, 1999; JUNEJA, 2019).

Contudo, a escolha do método a ser empregado em um treinamento dependerá do objetivo que se queira alcançar, seja para o desenvolvimento de competências, seja para a vivificação dos traços de liderança, o trabalho em equipe para a aprendizagem, ou mesmo para se alcançar outros objetivos peculiares às necessidades e interesses de cada empresa (SILVA, 2016).

Assim, dentre os objetivos dos jogos corporativos inclui-se a formação de equipes, resolução de problemas, aperfeiçoamento da liderança, aumento da confiança e das habilidades de comunicação, sendo que, nas tarefas propostas para os jogadores os desafios 
apresentados remetem ao desenvolvimento de atributos executivos indispensáveis aos participantes, conforme Quadro 1:

Quadro 1 - Desafios dos jogos de treinamento corporativos

\begin{tabular}{|c|l|}
\hline Atributos & \multicolumn{1}{|c|}{ Desafio/ Tarefas dos jogadores } \\
\hline União & $\begin{array}{l}\text { Os participantes devem se unir para que o grupo inteiro trabalhe em conjunto a } \\
\text { fim de realizar determinada tarefa; }\end{array}$ \\
\hline Criatividade & Os participantes devem pensar em soluções criativas para resolver problemas; \\
\hline Decisão & Os participantes devem tomar decisões, considerando os riscos associados; \\
\hline Superação & Os participantes devem ser incentivados a superar obstáculos; \\
\hline Comunicação & Os participantes devem perceber a importância de uma comunicação eficaz. \\
\hline
\end{tabular}

Fonte: Adaptado de Williams, Graham e Baker (2002)

Como se observa no Quadro 1, os jogos corporativos devem desenvolver nos participantes atributos essenciais das atividades executivas, levando em consideração as particularidades de cada treinamento e sua amálgama de diferentes características, desde backgrounds e personalidades (JUNEJA, 2019). Em decorrência, caso essa flexibilidade não seja contemplada, existem riscos que podem tornar o jogo de treinamento em uma experiência mal sucedida, conforme Quadro 2:

Quadro 2 - Riscos nos jogos de treinamento corporativos

\begin{tabular}{|c|l|}
\hline Riscos & \multicolumn{1}{c|}{ O problema do direcionamento } \\
\hline Obscuridade & As regras não estão enunciadas de forma clara; \\
\hline Divergências & Ocorrem muitos conflitos entre os participantes da equipe; \\
\hline Despreparo & O facilitador possui pouco conhecimento para condução da experiência; \\
\hline Desinteresse & $\begin{array}{l}\text { Os jogos se tornam desinteressantes, pois, o propósito ou significado da } \\
\text { experiência não foi absorvido pelos participantes. }\end{array}$ \\
\hline
\end{tabular}

Fonte: Adaptado de Silva; Franco (2018).

Esses riscos, se não observados, fazem com que a temática do jogo não atraia o interesse dos participantes, o que dificulta alcançar os resultados desejados. Comumente, a maior parte desses riscos ocorre por ingerência dos aplicadores (instituições, monitores, facilitadores, instrutores entre outros). Porém, esses fatores não anulam os benefícios e vantagens do uso dessa ferramenta.

\subsection{A Gestão do conhecimento na pós-modernidade}

A pós-modernidade se configura como uma nova postura em educação, renegando a prática tradicional na relação educador/aprendiz pela inserção de novas tecnologias cada vez mais sofisticadas no ensino aprendizagem.

Cada vez mais essas tecnologias são compartilhadas nas redes, o que requer relacionamentos contínuos e estratégicos com os stakeholders, a forma de tratamento dispensada a cada um deles, para se angariar benefícios (PUTNAM, 1996; ROWLEY, 1997; SCHNEIDER; SACHS, 2017).

$\mathrm{Na}$ literatura sobre GC, pode-se observar que, dentre as inúmeras definições propostas, os autores estabelecem-se conceitos direcionados para a criação de valor por meio da colaboração e compartilhamento do conhecimento com o objetivo de maximizar o desempenho organizacional.

Nessa linha de raciocínio, Davenport (1994) postula que a GC consiste no processo de captura, distribuição e efetivo uso do conhecimento. Ampliando essa definição, Silver (2000)

Perspectivas em Gestão \& Conhecimento, João Pessoa, v. 10, n. 2, p. 42-66, maio/ago. 2020. 
entende que a GC é uma área multidisciplinar que integra estratégia e processo de negócios, cultura e comunidade organizacional, colaboração, aprendizado, expertise e tecnologia.

Por sua vez, Menezes et al. (2017, p. 147) concebem a GC como "a capacidade de lidar de forma criativa com as diferentes dimensões do conhecimento". Ribeiro et al. (2017) afirmam que a GC contribui para maximizar o desempenho e os resultados organizacionais.

O ponto comum na percepção desses autores é que a GC constitui uma estratégia consciente de conseguir o conhecimento certo para a pessoa certa no momento certo, auxiliando as pessoas a compartilharem informação e colocá-la em prática de forma a melhorar a desempenho da organização $(\mathrm{HCl}, 2019)$.

Ao nos reportarmos aos autores seminais voltados para a GC, Nonaka e Takeuchi (1995) propõem a espiral do conhecimento, cuja metodologia parte do pressuposto de que existem duas formas principais de conhecimento, o tácito e o explícito. O conhecimento explícito se refere ao conhecimento codificável, articulado, tangível que pode ser transcrito em documentos, manuais, livros, enquanto o conhecimento tácito tem sua origem nas experiências, percepções e valores individuais adquiridas na prática dos processos, hábitos e rotinas de trabalho.

Por sua natureza, o conhecimento tácito pode constituir um ativo mais raro e valioso para a empresa, porém é mais difícil de ser identificado e utilizado, já que esse tipo de conhecimento reside dentro do indivíduo, enraizado em suas ações e, portanto, difícil de ser expresso em palavras. Por essas características, o conhecimento tácito raramente é compartilhado ou comunicado e tende a se perdendo quando o indivíduo deixa a organização (ARGOTE; INGRAM, 2000; MESO; SMITH, 2000).

Ainda em meados do século passado, Polanyi (2010) inviabilizava a separação entre o conhecimento tácito e o conhecimento explícito o que torna necessária a função de ambos no processo do conhecimento. Afirmava que todo conhecimento tem um elemento tácito, embora o grau de tacitude varie. A questão de como o conhecimento tácito (por exemplo, experiência e ideias) é convertido em conhecimento explícito (por exemplo, tecnologia) para ser compartilhado entre todos os envolvidos se torna imprescindível para conectar as fontes de geração com as necessidades de aplicação do conhecimento. O conhecimento explícito, também, pode ser desenvolvido e instrumentalizado como um elemento facilitador para introduzir estímulos externos às partes interessadas locais. (BAGGIO; COOPER, 2010; HALLIN; MARNBURG, 2008; NIEVES; QUINTANA; OSORIO, 2014; SHAW; WILLIAMS, 2009).

Nonaka e Takeuchi (1997) propõem um modelo de criação de um novo conhecimento a partir da conversão do conhecimento tácito e do conhecimento que envolve desde o indivíduo até o grupo, a organização e o ambiente. O modelo SECl (Socialização, Externalização, Combinação e Internalização) ou espiral do conhecimento (Figura 1) baseia a conversão do conhecimento em quatro etapas:

a) Socialização: compartilhamento de experiências, habilidades técnicas e modelos mentais, convertendo conhecimento tácito em conhecimento tácito;

b) Externalização: indivíduos expressam suas experiências por meio de analogias, metáforas, modelos e hipóteses, transformando o conhecimento tácito em conhecimento explícito;

c) Combinação: combinação de conhecimentos através de documentos, conversas, reuniões, gerando novos conhecimentos explícitos a partir de conhecimentos tácitos;

d) Internalização: desenvolvimento de um conhecimento operacional a partir da transformação do conhecimento explícito em conhecimento tácito. 
Figura 1 - Espiral do conhecimento

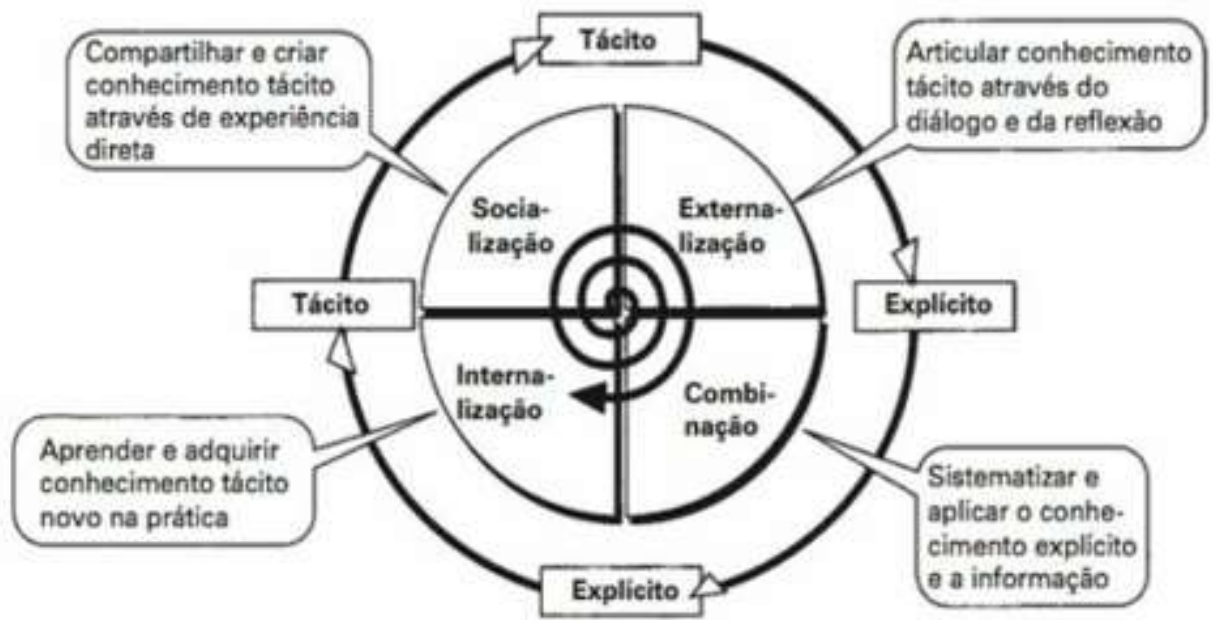

Fonte: Nonaka e Takeuchi (2008, p. 24)

Na prática, a socialização remete o compartilhar do conhecimento tácito ensejando a proximidade física para a interação direta entre os indivíduos (NONAKA; KONNO, 1998). Todavia, a socialização em si mesma é uma forma limitada ao propósito da criação de conhecimento, visto que, se o conhecimento não se tornar explícito, será de pouca valia para toda a organização (NONAKA; TAKEUCHI, 2008),

Pode-se visualizar no modelo que as quatro formas de conversão de conhecimento devem ser gerenciadas articuladamente e ciclicamente, como uma espiral. Por essa razão, a espiral do conhecimento remete ao comprometimento pessoal, em que, gradualmente, os conceitos úteis e valiosos alcançam uma ampla aceitação e, assim, são progressivamente cristalizados em vários processos de conversão entre o conhecimento tácito e o explícito que perpassam desde o indivíduo até o grupo e a organização, ou seja, um novo conceito é reproduzido em um grupo, extrapolando o nível individual, desenvolvido e esclarecido evolutivamente.

No aspecto organizacional, o conhecimento é específico ao contexto e relacional, se caracterizando por um processo dinâmico que abrange os vários níveis organizacionais, onde o conhecimento de cada indivíduo é amplificado e absorvido como parte do conhecimento da organização, ao criar um ambiente propício que estimule e facilite a criação e troca de conhecimento (NONAKA; TAKEUCHI, 1997). Sendo assim, é visto como o recurso mais importante da organização, trazendo dificuldades para que os concorrentes possam percebêlo e imitá-lo, tornando-se importante fonte de vantagem competitiva (ARGOTE; INGRAM, 2000; INKPEN; TSANG, 2016).

A aquisição do conhecimento constitui o ponto de partida do processo de gestão do conhecimento manifestando-se pela capacidade de aprendizagem de seus indivíduos ou pela integração de conhecimento de origem externa (LÓPEZ-SÁEZ et al., 2010; WHITE; CICMIL, 2016). O armazenamento do conhecimento consiste na capacidade da organização se apropriar e institucionalizar o conhecimento adquirido (LIN; CHANG; TSAI, 2016). Por sua vez, a distribuição do conhecimento institucionalizado permite que os indivíduos da organização tenham acesso a uma base comum de conhecimento, promovendo sua utilização em novos processos (LEFEBVRE et al., 2016).

Também, na sociedade em rede, caracterizada por Castells (1999) como sociedade da informação e do conhecimento, as empresas precisam se adaptar ou ajustar de algum modo e, para isso é importante aprender a considerar suas bases de conhecimento emergente que,

Perspectivas em Gestão \& Conhecimento, João Pessoa, v. 10, n. 2, p. 42-66, maio/ago. 2020. 
geralmente encontram nas intranets uma importante aliada para disseminação de forma estruturada da comunicação e o engajamento colaborativo.

Nesse engajamento colaborativo, em consonância com os princípios da GC, o êxito do empreendimento está condicionado ao desenvolvimento de características organizacionais adequadas que propiciem o desenvolvimento dos quatro fatores: aquisição, armazenamento, distribuição e utilização do conhecimento (CHEN; HUANG; SIAO, 2010; LIAO; CHUANG; TO, 2011; GONZALEZ; MARTINS; TOLEDO, 2014).

Ocorre que, esses quatro fatores são desenvolvidos internamente e de forma bastante particular pelas organizações, apesar de influenciarem de forma direta o processo de GC, visto que, resultam em maneiras e capacidades distintas de construir capital intelectual e obter aumento da capacidade inovadora (CHEN; HUANG; SIAO, 2010; GONZALEZ; MARTINS; TOLEDO, 2014; TORUGSA; O'DONOHUE, 2016). Dentre os objetivos essenciais da GC, Bukowitz; Williams, 2002; Boder, 2006 destacam três pontos essenciais, conforme Quadro 3:

Quadro 3 - Atributos e procedimentos essenciais da GC

\begin{tabular}{|l|l|}
\hline Atributos & \multicolumn{1}{|c|}{ Procedimentos essenciais } \\
\hline Inteligência & $\begin{array}{l}\text { Fazer com que a organização atue da maneira mais inteligente possível, a fim de } \\
\text { garantir sua viabilidade e sucesso geral; }\end{array}$ \\
\hline Valor & Criar valor para o cliente e comunica-lo ao mercado; \\
\hline Singularidade & Criar posicionamento inovador que seja de difícil imitação pela concorrência. \\
\hline
\end{tabular}
Fonte: Adaptado de Bukowitz e Williams (2002) e Boder (2006)

Esses atributos e procedimentos essenciais propostos pela GC nas redes contribuem para a criação, renovação e aplicação dos conhecimentos estratégicos na organização, uma vez que, as ligações fortes que se estabelecem entre as partes favorecem a criação e a transferência de conhecimento e, em particular, a interatividade dinâmica entre o conhecimento tácito e explícito.

Assim, a GC pode estimular a colaboração por meio de plataformas e ferramentas tecnológicas, como por exemplo, os fóruns de discussão online. Através desse recurso, o conhecimento tácito pode ser criado, alavancado, compartilhado e coletado para posterior codificação em um formato explícito, permitindo sua reutilização em diversos contextos, o que propicia ambiente favorável para a inovação e criatividade (CAVUSGIL, CALANTONE; ZHAO, 2003; DU PLESSIS, 2007).

Particularmente, em relação às organizações em rede, Argote e Ingram (2000), McGrath e Argote (2001) postulam que, em nossa contemporaneidade, o conhecimento está embutido em três elementos essenciais das organizações - membros, ferramentas e tarefas e nas redes formadas pelo cruzamento deles como elementos de funcionalidades. Membros correspondem aos componentes humanos da organização, Ferramentas são os componentes tecnológicos, enquanto as Tarefas refletem os objetivos, propósitos e intenções da organização, conforme Quadro 4:

Quadro 4 - Funcionalidades das redes

\begin{tabular}{|l|l|}
\hline Redes & \multicolumn{1}{|c|}{ Funcionalidades } \\
\hline Rede membros-membros & Rede social da organização. \\
\hline Rede tarefas-tarefas & Sequência de tarefas ou rotinas da organização. \\
\hline Rede ferramentas-ferramentas & Combina as tecnologias da organização. \\
\hline Rede membros-tarefas & Designa membros para determinadas tarefas. \\
\hline A rede tarefas-ferramentas & $\begin{array}{l}\text { Especifica as ferramentas que serão utilizadas para executar } \\
\text { determinadas tarefas. }\end{array}$ \\
\hline Rede membros-ferramentas- & Designa membros para executar determinadas tarefas com \\
\hline
\end{tabular}

Perspectivas em Gestão \& Conhecimento, João Pessoa, v. 10, n. 2, p. 42-66, maio/ago. 2020. 
\begin{tabular}{|l|l}
\hline tarefas & determinadas ferramentas.
\end{tabular}

Fonte: Adaptado de Argote e Ingram (2000); Mcgrath e Argote (2001)

Como se pode observar no quadro 4, esses elementos básicos formam sub-redes e, desse modo, o conhecimento pode ser transferido por meio da movimentação dos membros, tarefas e ferramentas ou redes onde o conhecimento é incorporado de uma unidade social para outra ou por modificação desses elementos. Por exemplo, movimentando o pessoal de uma unidade organizacional para outra, assim o conhecimento adquirido em uma unidade pode ser transferido para outra.

Nessa perspectiva, as redes descentralizadas tendem a proporcionar melhor funcionalidade e, consequente, resultados mais satisfatórios.

Ainda em relação à transferência de conhecimento, geralmente, o conhecimento não se encontra de forma explícita e é transmitido de forma tácita, exigindo tempo significativo e, consequentemente, retardando o desenvolvimento de novos produtos, serviços, competências e otimização de processos (GRANT, 1996; SROKA; CYGLER; GAJDZIK, 2014; KHAN, 2016). Além disso, o conhecimento tácito mais valioso pode não ser facilmente capturado de forma explícita por diversas razões, tais como a dificuldade em explicá-lo, sua incerteza e mutabilidade, contexto específico demais ou politicamente sensível (GARDNER, 1998).

Assim, para que haja a transferência do conhecimento deve existir uma disposição do indivíduo e/ou grupo de compartilhar o conhecimento criado ou adquirido (GIBBERT; KRAUSE, 2002), sendo necessário motivação e vontade das partes (KHAN, 2016) e depende das características dos indivíduos e alinhamento entre as partes envolvidas (OLIVEIRA JUNIOR, 2007), o que torna importante a criação de um ambiente onde haja confiança mútua e estímulo à cooperação, podendo assim, superar a tendência natural de se proteger os conhecimentos da empresa.

Resulta, então para que os membros da rede devam ser motivados a participarem voluntariamente e contribuir com ideias e conhecimentos para o "bem coletivo", o que pode gerar conhecimento e ideias coletivas, beneficiando a todos (JOLINK; DANKBAAR, 2010). Além disso, fatores como redes sociais, tecnologias, rotinas e mobilidade de pessoal podem também contribuir para a transferência do conhecimento (ARGOTE; FAHRENKOPF, 2016).

\subsection{Gestão do conhecimento e tecnologia educacional e andragogia}

De acordo com Chiavenato (2009) e Mangal; Mangal (2009), a tecnologia educacional procura identificar qual a ferramenta tecnológica mais adequada e apropriada que atenda às necessidades educacionais e propósitos dos estudantes e da sociedade em um tempo e espaço definidos. Não se trata apenas de recursos audiovisuais, materiais e equipamentos tecnológicos, mas sim, abrange em seu escopo o planejamento, a estruturação, a implementação e a avaliação do ensino-aprendizagem, com o objetivo de obter os melhores resultados baseados na relação custo-benefício.

A andragogia estuda o processo de ensino e aprendizagem em adultos, entendendo que o educando adulto é o sujeito ativo de seu próprio aprendizado que, enquanto ser consciente e reflexivo, volta-se para a apreensão de conteúdos que lhe sejam mais significativos e relevantes que possam ser aplicados em sua realidade pessoal e profissional (KNOWLES, HOLTON III; SWANSON, 2009; PRINCE, 2004; CAVALCANTI; GAYO, 2005; CARVALHO, 2017).

Ao aliar tecnologia educacional aos princípios da andragogia, os jogos de treinamento corporativos promovem recursos educacionais para a aprendizagem voltados para alcançar resultados tangíveis, por intermédio de uma abordagem prática que busca aumentar a

Perspectivas em Gestão \& Conhecimento, João Pessoa, v. 10, n. 2, p. 42-66, maio/ago. 2020. 
efetividade da educação corporativa. Knowles; Holton III; Swanson (2009) propõem seis princípios básicos para a andragogia: a necessidade de saber do adulto aprendiz; autoconceito; experiência anterior; prontidão para a aprendizagem; orientação para a aprendizagem; motivação para novos aprendizados.

Essa disposição, ou seja, a capacidade de aprender continuamente e adquirir novos conhecimentos com vistas a melhorar o desempenho é denominada Aprendizagem Organizacional (RUAS; ANTONELLO; BOFF, 2006). Dentre os estudos mais recentes, Frogeri et al. (2019) propõem um modelo teórico relacional entre as temáticas de aprendizagem organizacional e gestão do conhecimento.

Portanto, ao se dispor a aprender é primordial que a organização tenha habilidade para transferir conhecimentos de forma rápida e eficiente (SILVA; FLEURY, 2012). No entanto, para gerar melhorias substantivas de desempenho, as melhores práticas devem considerar os contextos organizacionais diferentes. Se o foco for apenas o processo de transferência e não o que está sendo transferido de fato, pode-se obter apenas um resultado "regular" (ATHERTON; PRICE, 2008).

Por isso, na perspectiva da GC, o aprendizado é um processo de produzir conhecimento em que se transfere o conhecimento explícito (informação) para que as pessoas gerem o conhecimento tácito, que consiste no processo de interação, comunicação e coordenação de conhecimento ou de experiência, todavia, para que esse processo efetivamente ocorra, requer a criação de clima organizacional propício que viabilize a troca de ideias e favoreça o diálogo (STRAUHS; DO, 2012). Ou seja, somente com o compartilhamento de conhecimento não se maximiza a eficácia organizacional. Os destinatários com os quais o conhecimento é compartilhado devem reconhecer a utilidade e o valor do conhecimento para impulsionar esse processo (KIM; YUN, 2015).

Em síntese, no cenário competitivo e dinâmico de contínuas mudanças, a aprendizagem organizacional constitui um processo coletivo com o objetivo de adquirir competências, para melhorar o desempenho e enfrentar novas situações e resolver problemas (HUNG et al., 2011; SÁNCHEZ; VIJANDE; GUTIÉRREZ, 2010).

\section{PROCEDIMENTOS METODOLÓGICOS}

A delimitação temporal da pesquisa constitui um recorte transversal, ou seja, visa captar um determinado momento em um ponto específico no tempo. Serão coletadas informações que remetam ao início de operação da CJC, bem como de sua parceria com a rede da Catalyst Global para entender como ocorre a GC e quais benefícios para lidar com as novas situações que a CJC obteve em consequência dessa parceria.

Trata-se de uma pesquisa de abordagem qualitativa de cunho descritivo, na qual se delimitou a aplicação da GC em uma única empresa de jogos de treinamento corporativo em rede de relacionamento, tendo como pergunta de pesquisa: como a GC pode proporcionar vantagem competitiva nas empresas de jogos de treinamento corporativos inseridas em uma rede de relacionamento?

Foram pesquisados os setores da CJC que interagem diretamente com a Catalyst e, dentro destes, identificadas as possíveis unidades de observação, como recomenda Yin (2015), quais sejam diretores, líderes de equipes de criação e demais sujeitos que participam ou participaram mais ativamente dos fóruns anuais promovidos pela Catalyst Global para posterior realização de entrevistas, de acordo com a disponibilidade destes.

Segundo Marconi e Lakatos (2017, p. 180), "a coleta de dados é a etapa da pesquisa em que se inicia a aplicação dos instrumentos elaborados e das técnicas selecionadas, a fim de efetuar a coleta dos dados previstos". Estudos de caso geralmente combinam métodos de 
coleta de dados tais como documentos, entrevistas, questionários e observações (EISENHARDT, 1989).

Nesse sentido, a pesquisa é um estudo de caso, uma vez que se utiliza de uma única empresa investigada, à luz do que explica Severino (2007, p. 121), "pesquisa que se concentra no estudo de um caso particular, considerado representativo de um conjunto de casos análogos, por ele significativamente representativo". Por sua vez, Gil (2010) entende que a credibilidade de um estudo de caso tem muito a ver com a adequação de seus resultados aos pontos de vista de seus participantes.

Para os propósitos deste estudo de caso foram utilizadas entrevistas, observações e análise documental. As entrevistas semiestruturadas, com roteiro previamente elaborado foram realizadas em 09 de maio, com o gestor e nos dias 15 e 16 de maio de 2019, com três colaboradores da CJC que atuam na área de Operações (C1), Logística (C2), Gestão de Projetos e área Comercial (C3), sendo que, atuam também, simultaneamente, no setor de criação, desenvolvimento e customização dos jogos de treinamento corporativos.

Em consonância com os procedimentos éticos, os resultados foram apresentados aos participantes da pesquisa, antes da conclusão da análise, a fim de se obter feedback das percepções entre as respostas e a realidade fática, dando assim credibilidade à qualidade dos dados obtidos.

\section{APRESENTAÇÃO E ANÁLISE DOS RESULTADOS}

A afirmação orientadora foi confirmada. A GC nas redes de relacionamento dos jogos de treinamento corporativo favorece a integração entre o conhecimento tácito e explícito promovendo diferencial competitivo em relação à concorrência.

O emprego da GC aplicado às empresas de jogo de treinamento corporativo favorece o alcance de vantagem competitiva nas redes de relacionamento por contemplarem os desafios da pós-modernidade, minimizarem os riscos por intermédio da atualização e compartilhamento do conhecimento entre os membros ao possibilitar a inovação e a criatividade como solução eficaz.

$\mathrm{Na}$ perspectiva de Creswell (2014) a apresentação e a análise dos resultados contemplam a categorização, codificação, representação e formulação de uma interpretação das evidências coletadas. E, como recomenda Yin (2015) a estratégia analítica geral com base nas proposições teóricas direciona a análise do estudo de caso.

Quadro 5 - Características da Rede de Relacionamento da CJC/Catalyst

\begin{tabular}{|c|c|}
\hline Categorias & Descrição \\
\hline Dados da Catalyst Global & $\begin{array}{l}\text { - Rede descentralizada de empresas de jogos; } \\
\text { - } 30 \text { anos de existência (1988); } \\
\text { - Possui sedes na Austrália e Inglaterra; } \\
\text { - Mais de } 40 \text { representantes no mundo; } \\
\text { - Representantes na América: Brasil, Chile, Colômbia, Costa Rica, } \\
\text { Curaçao, México, República Dominicana e Estados Unidos; } \\
\text { - Criação, desenvolvimento e aperfeiçoamento de produtos; } \\
\text { - Produção de material de jogos e material de marketing; } \\
\text { - Intermediação entre os membros da rede, intervindo na } \\
\text { resolução de possíveis conflitos e interesses. }\end{array}$ \\
\hline Dados da CJC & $\begin{array}{l}\text { - Empresa de jogos corporativos; } \\
\text { - } 20 \text { anos de existência; } \\
\text { - Pertence à rede da IEN Escola de Negócios e Catalyst Global; }\end{array}$ \\
\hline
\end{tabular}

Perspectivas em Gestão \& Conhecimento, João Pessoa, v. 10, n. 2, p. 42-66, maio/ago. 2020. 


\begin{tabular}{|c|c|}
\hline & - Possui ampla rede de fornecedores. \\
\hline $\begin{array}{l}\text { Relacionamento com os } \\
\text { stakeholders }\end{array}$ & $\begin{array}{l}\text { - Fornecedores, freelancers e clientes estão presentes desde o } \\
\text { início das atividades da CJC (1999); } \\
\text { - O relacionamento com a IEN e a Catalyst Global iniciou-se em } \\
2012 ; \\
\text { - IEN e Catalyst Global trouxeram benefícios de forma } \\
\text { complementar à CJC. }\end{array}$ \\
\hline $\begin{array}{l}\text { Benefícios para a CJC ao fazer } \\
\text { parte da rede Catalyst Global } \\
\text { - } \\
\begin{array}{l}\text { Benefícios da CJC pelo } \\
\text { relacionamento com a Catalyst } \\
\text { Global }\end{array}\end{array}$ & $\begin{array}{l}\text { - Conquista de selo internacional; } \\
\text { - Troca de informações entre os membros da rede; } \\
\text { - Criação contínua de conhecimento; } \\
\text { - Foco no cliente; } \\
\text { - Acesso a mais recursos do que a concorrência; } \\
\text { - Diferenciação de produto. } \\
\text { - Aumento do portfólio de produtos; } \\
\text { - Legitimação internacional; } \\
\text { - Troca de experiências; } \\
\text { - Compartilhamento de informações e de conhecimentos; } \\
\text { - Suporte contínuo. }\end{array}$ \\
\hline $\begin{array}{l}\text { Aspectos gerais } \\
\text { Treinamentos }\end{array}$ & $\begin{array}{l}\text { Foco: temas mais trabalhados nos treinamentos: autonomia, } \\
\text { criatividade e inovação; temas menos procurados: liderança e } \\
\text { comunicação. } \\
\text { Desafio maior: Capturar a atenção dos treinandos. } \\
\text { Dificuldades: busca de significado e sentido para o treinamento } \\
\text { que impacte positivamente no dia-a-dia dos treinandos; } \\
\text { - Adaptação dos produtos de acordo com a cultura local. }\end{array}$ \\
\hline Estratégias básicas & $\begin{array}{l}\text { - Confidencialidade; } \\
\text { - Acompanhar a evolução das necessidades dos clientes. }\end{array}$ \\
\hline Inovação & $\begin{array}{l}\text { - Customização dos produtos como fator de inovação; } \\
\text { - Elaborado de acordo com as especificidades e necessidades do } \\
\text { cliente. }\end{array}$ \\
\hline Visão de Futuro & $\begin{array}{l}\text { Crescimento da empresa: } \\
\text { - criação de escritórios regionais em outras cidades, já que } \\
\text { atuação da CJC é restrita às regiões Sudeste e Sul do país. }\end{array}$ \\
\hline
\end{tabular}

Fonte: Elaborado pelos autores com base nas respostas do gestor da CJC

Nas respostas do gestor pode-se observar a importância da fidelização e a busca da criação de valor para seus stakeholders cujos relacionamentos, com a maioria desses agentes teve início com o surgimento da empresa propiciando benefícios recíprocos. Os temas mais trabalhados nas temáticas dos jogos corporativos são autonomia, criatividade e inovação dos participantes, tendo como foco principal as necessidades dos clientes. 
Quadro 6 - Síntese das respostas dos colaboradores da CJC

\begin{tabular}{|c|c|}
\hline Categorias & Descrição \\
\hline $\begin{array}{l}\text { Benefícios para a CJC ao fazer } \\
\text { parte da rede }\end{array}$ & $\begin{array}{l}\text { - Gama de material para aplicação }(C 1, C 2) \text {; } \\
\text { - Aumento de } 20 \text { para mais de } 120 \text { jogos diferentes }(C 1, C 2) ; \\
\text { - Atendimento a vários públicos, com temáticas diferentes }(C 1, C 2) \text {; } \\
\text { - Diversidade de produtos (C3); } \\
\text { - Velocidade nos lançamentos (C3). }\end{array}$ \\
\hline $\begin{array}{l}\text { Relacionamento com os } \\
\text { stakeholders }\end{array}$ & $\begin{array}{l}\text { - Aquisição de maior equipe de vendas e maior acesso a clientes } \\
\text { corporativos com a IEN; } \\
\text { - Aquisição de maior carga técnica e ampliação do portfólio de } \\
\text { produtos com a Catalyst Global. }\end{array}$ \\
\hline $\begin{array}{l}\text { Competências adquiridas pelo } \\
\text { setor }\end{array}$ & $\begin{array}{l}\text { - Delegação de tarefas e responsabilidades (C1); } \\
\text { - Criatividade no desenvolvimento de jogos (C1); } \\
\text { - Habilidade multitask (C2); } \\
\text { - Resiliência (C2); } \\
\text { - Foco em cada projeto (C2); } \\
\text { - Alinhamento de demanda com o cliente (C2); } \\
\text { - Colaboração e cooperação (C3); } \\
\text { - Integração (C3); } \\
\text { - Liderança (C3); } \\
\text { - Tomada de decisão (C3); } \\
\text { - Comunicação (C3). }\end{array}$ \\
\hline Estratégia & $\begin{array}{l}\text { - Adaptar os produtos para o público brasileiro (C1); } \\
\text { - Entregar o produto com o melhor custo-benefício (C2); } \\
\text { - Entender as necessidades do cliente (C3). }\end{array}$ \\
\hline $\begin{array}{l}\text { Compartilhamento de } \\
\text { conhecimento }\end{array}$ & $\begin{array}{l}\text { - Troca de informação e de experiências (C1); } \\
\text { - Pesquisa e padronização de material (C1); } \\
\text { - Proximidade das relações na rede (C3); } \\
\text { - Velocidade na troca de informação (C3); } \\
\text { - Agilidade de comunicação (C3). }\end{array}$ \\
\hline Inovação & $\begin{array}{l}\text { - Apresentação de projetos novos para a rede (C1); } \\
\text { - Discussão de conceitos que são tendências nos mercados (C1); } \\
\text { - Discussão em fórum virtual (C3); } \\
\text { - Adaptação cultural dos jogos (C3); } \\
\text { - Brainstorming realizado entre os membros da rede (C3). }\end{array}$ \\
\hline Dificuldades & $\begin{array}{l}\text { - Questões culturais e de idioma }(\mathrm{C} 1) \text {; } \\
\text { - Perfil do público }(\mathrm{C} 1) \text {; } \\
\text { - Comunicação com o cliente }(\mathrm{C} 1) ; \\
\text { - Prazo curto para alta demanda }(\mathrm{C} 1, \mathrm{C} 2) ; \\
\text { - Alinhamento das expectativas dos clientes com o que é possível } \\
\text { ser entregue (C2); } \\
\text { - Adequação do produto ao orçamento do cliente (C2); } \\
\text { - Adaptação contínua dos produtos às necessidades de treinamento } \\
\text { dos clientes (C3). }\end{array}$ \\
\hline Visão de Futuro & $\begin{array}{l}\text { - Aumento de intercâmbios culturais e de conhecimento com os } \\
\text { membros da rede }(C 1, C 2) \text {; }\end{array}$ \\
\hline
\end{tabular}

Perspectivas em Gestão \& Conhecimento, João Pessoa, v. 10, n. 2, p. 42-66, maio/ago. 2020. 
\begin{tabular}{|l|l|}
\hline & - Expectativa de crescimento e expansão da CJC (C3); \\
- Maior potencial para criação e customização dos produtos (C3).
\end{tabular}

Fonte: Elaborado pelos autores com base nas respostas dos colaboradores da CJC

Nas respostas dos colaboradores se evidenciam a importância das proximidades das relações nas redes para troca de informação e de experiências com ênfase no alinhamento das expectativas dos clientes com os novos produtos a serem lançados.

Pode-se observar nas respostas dos entrevistados em relação aos desafios, a importância das soluções criativas e da comunicação eficaz como procedimentos presentes e imprescindíveis (WILLIAMS; GRAHAM; BAKER, 2002).

Quanto aos riscos que podem comprometer o empreendimento (dentre os quais, o mais prejudicial seria o desinteresse dos treinandos), esses parecem, por um lado, minimizados pela adoção dos princípios do modelo de andragogia que, com base no desenvolvimento da autonomia dos treinandos, proporciona atitudes proativas, interesse pelo conteúdo e, portanto, motivação para o aprendizado, por outro, o estabelecimento de regras claras na rede, evita interpretações dúbias, procedimento esse que, de certa forma evita o surgimento de conflitos maiores (SILVA; FRANCO, 2018).

Outro ponto a ser destacado diz respeito a atuação na rede em que a parceria da IEN da CJC com a Catalyst Global contempla as relações membros-membros tarefas-tarefas, ferramentas-ferramentas, membros-ferramentas-tarefas pela proximidade das relações na rede, compartilhamento do conhecimento por meio de troca e velocidade na troca de informação e de experiências; pesquisa e padronização de material e agilidade na comunicação, o que favorece por intermédio da delegação de tarefas que possibilitar atendimento a vários públicos, diversidade de produtos com temáticas diferentes, velocidade nos lançamentos de novos produtos (ARGOTE; INGRAM, 2000).

Esses procedimentos buscam contemplar os desafios diários, minimizar os riscos e fortalecer os relacionamentos nas redes, seis fatores se evidenciam como determinantes para o alcance de vantagem competitiva.

Quadro 7 - Fatores para o alcance de vantagem competitiva

\begin{tabular}{|l|l|}
\hline \multicolumn{1}{|c|}{ Desafios } & \multicolumn{1}{c|}{ Procedimentos recomendados } \\
\hline Relacionamento & Relacionamento proativo com os diferentes stakeholders \\
\hline Tempo & $\begin{array}{l}\text { Descentralização e compartilhamento das informações nas redes de relacionamento } \\
\text { em tempo real }\end{array}$ \\
\hline Cultura & Adaptação do conhecimento à cultura local \\
\hline Tecnologia & O emprego da tecnologia educacional como processo atrativo e eficiente \\
\hline Educação & Utilização dos seis princípios do modelo andragógico \\
\hline Atualização & Atualização contínua dos jogos como estratégia de crescimento \\
\hline
\end{tabular}

Fonte: Elaborado pelos autores

- Fator 1. Relacionamento proativo com os stakeholders na rede

O relacionamento proativo da CJC nas redes de relacionamento possibilitou acesso a uma carteira maior de clientes corporativos e maior equipe de vendas enquanto a Catalyst Global ampliou o catálogo de jogos corporativos e proporcionou acesso, troca e compartilhamento de conhecimento com empresas membros em diversos países.

Outro ponto observado diz respeito à participação voluntária dos membros da Catalyst Global nas discussões e o modo como se ajudam mutuamente, contribuindo para a geração de novas ideias e conhecimentos coletivos, o que beneficia a todos da rede (JOLINK e DANKBAAR,

Perspectivas em Gestão \& Conhecimento, João Pessoa, v. 10, n. 2, p. 42-66, maio/ago. 2020. 
2010). Silva e Fleury (2012) ressaltam que a habilidade de transferência de conhecimentos, quando realizada de maneira eficiente e rápida, pode favorecer a aprendizagem organizacional, que se constitui de um processo coletivo que visa obter competências, melhorar o desempenho, enfrentar novas situações e resolver problemas (HUNG et al., 2011; SÁNCHEZ, VIJANDE; GUTIÉRREZ, 2010).

Constatou-se, também, a postura proativa propicia o surgimento de novas ideias para desenvolvimento de jogos através da discussão nos fóruns virtuais e presenciais promovidos pela Catalyst Global, ao empregar a técnica do brainstorm entre os membros da rede. Através da utilização de fóruns colaborativos, o conhecimento flui além das fronteiras organizacionais, o que permite a troca, o compartilhamento, a recombinação e a criação de novos conhecimentos, de forma a promover inovação e criatividade (CAVUSGIL, CALANTONE ;ZHAO, 2003; DU PLESSIS, 2007).

Assim, de forma complementar, a IEN e a Catalyst Global contribuem positivamente no desempenho da CJC. Com ampla variedade de produtos disponível e maior equipe de vendedores foi possível oferecer os treinamentos a uma quantidade maior de clientes, em decorrência da relação de integração entre os envolvidos, o que resulta em benefícios e, consequente vantagem competitiva para as empresas que participam da rede (PUTNAM, 1996; ROWLEY, 1997; SCHNEIDER; SACHS, 2017).

- Fator 2. Descentralização e compartilhamento das informações na rede

A rede Catalyst Global se caracteriza por ser uma rede descentralizada, intermediando e intervindo na resolução de conflitos e interesses, quando necessário.

Devido à sua presença em vários países do mundo, a rede Catalyst Global propicia o alcance de legitimação internacional e relacionamentos entre diversas culturas que favorecem as empresas associadas nesse empreendimento. Os membros se beneficiam com a ampliação e diversidade de produtos e troca de experiências e, consequentemente, a transferência e o compartilhamento contínuo de informações e de conhecimentos.

Tal afirmação corresponde na literatura sobre redes interorganizacionais ao pressuposto de que, atualmente, existe uma tendência em todo mundo à descentralização e, desse modo, as redes descentralizadas e bem coordenadas propiciam maior cooperação e, consequentemente, melhor alcance de resultados e funcionalidade (MELLO, 2010; PIES, BAGGIO e ROMEIRO, 2016).

Provan e Kenis (2008) afirmam que as empresas em redes visam obtenção de legitimidade, atendimento eficiente de clientes, atração de recursos e resolução de problemas complexos. Lin e Lin (2016) corroborando com esse raciocínio concebe que a presença da empresa em uma rede pode trazer benefícios como compartilhamento de riscos, diminuição dos custos de transação, poder maior de mercado e melhor acesso a recursos como capital e informações. Além desses benefícios, também é possível adquirir conhecimento sobre novas tecnologias, aprendizagem, alcance de objetivos e esforços colaborativos em inovação (JOLINK; DANKBAAR, 2010).

Em relação ao compartilhamento de conhecimento entre os membros da rede, constatou-se a importância de fóruns online e presenciais, realizados anualmente, revezandose entre o escopo regional e o escopo global. Por ser dinâmico e proporcionar comunicação mais ágil e rápida, os fóruns online é a ferramenta mais utilizada pelos membros. Por meio dela, os membros trocam experiências, compartilham conhecimento, pedem e recebem sugestões para aplicação de jogos corporativos, de acordo com diversos requisitos, tais como quantidade e tipo de público.

Assim, pode-se inferir que, sendo participante da rede, a CJC obtém vários benefícios ao ter acesso a mais recursos do que a concorrência e diferenciação de produto. $\mathrm{O}$ acesso a 
esses recursos propicia vantagem competitiva, o que faz o conhecimento alcançado seja difícil de ser copiado pela concorrência (BUKOWITZ; WILLIAMS, 2002; BODER, 2006).

\section{- Fator 3. Adaptação do conhecimento à cultura local}

Constatou-se na pesquisa que existem algumas dificuldades devido às questões culturais de cada país, bem como de idioma, especialmente quanto ao significado das palavras.

$\mathrm{Na}$ questão do idioma, o impacto é mais sentido em relação à interferência da linguagem e ambiguidade da mensagem que pode ter entendimento diferente de acordo com o país. O processo de compartilhamento de conhecimento pode ser influenciado por uma cultura mais individualista ou coletivista. Na cultura individualista, existe uma preferência por meios formais de comunicação, de forma a externalizar e combinar a criação e transferência do conhecimento. Já na cultura coletivista, opta-se pelos meios informais, ou seja, socializando e internalizando a criação e transferência do conhecimento (KORBI; CHOUKI, 2017).

Temos, então, um processo de liberdade criativa que a CJC possui em relação à Catalyst Global, através da modificação do conhecimento explícito (manuais para aplicação dos jogos) para a adequação à realidade e cultura locais como elemento facilitador e motivador das relações entre o instrutor e os treinandos (BAGGIO; COOPER, 2010; HALLIN; MARNBURG, 2008; NIEVES; QUINTANA; OSORIO, 2014; SHAW; WILLIAMS, 2009).

\section{- Fator 4. A tecnologia torna o processo atrativo e eficiente}

Em relação ao processo de incorporação das novas tecnologias da educação por meio dos jogos corporativos; salienta-se o aspecto tanto global quanto regional que é possível se estabelecer na dinâmica entre os agentes da rede no sentido de adaptar e mesmo alterar os jogos para atender às demandas que se apresentam e, dessa forma, atualizar os grupos participantes.

Os aspectos globais e regionais que podem ser trabalhados nos jogos corporativos com o emprego da tecnologia educacional buscam identificar a ferramenta mais pertinente para determinado público e sua contínua adaptação em decorrência das necessidades desse mesmo público.

De maneira geral, a incorporação das novas tecnologias de educação nos jogos corporativos constitui uma atitude pragmática do facilitador com vistas a tornar o processo atrativo e ao mesmo tempo eficiente.

Dentre os temas mais trabalhados pela CJC para seus clientes, está o desenvolvimento da autonomia do funcionário, acompanhado dos processos de criatividade e inovação. Curiosamente, um dos temas menos procurados diz respeito à liderança e comunicação, embora esses temas fossem bastante procurados no passado.

Um dos maiores desafios presentes na aplicação dos jogos corporativos está em conseguir manter a atenção dos funcionários, uma vez que existem muitas formas de distração, falta de interesse e demandas de serviços que estão sendo postergadas em função do treinamento.

Assim, os jogos corporativos precisam ser adaptados e customizados levando em consideração esses aspectos, de modo que possa transmitir significado e sentido para os treinandos e consequentemente, despertando interesse, atenção e colaboração para as atividades propostas. 


\section{- Fator 5. Utilização dos seis princípios da Andragogia}

Os seis princípios da andragogia, ao considerar a experiência anterior do aprendiz e modificar seu autoconceito, atua como fator motivacional para a prontidão e, consequente orientação para a aprendizagem em que, a conscientização da necessidade de incorporar novos saberes propicia sentido para a efetiva participação nos jogos corporativos,

A falta de sentido para os treinandos constituem um dos maiores riscos que podem tornar o treinamento mal sucedido como ressalta Silva; Franco (2018) ao destacar que, se o significado da experiência não for absorvido pelos participantes, a comunicação se torna absolutamente deturpada ou inexistente, por falta de sintonia entre emissor e receptor.

Como competências organizacionais adquiridas no desempenho das atividades de suas funções, os colaboradores da CJC destacaram o desenvolvimento de habilidades multitarefas, resiliência, alinhamento da demanda com o cliente.

Prahalad e Hamel (1990) afirmam que a aprendizagem organizacional coletiva, ou seja, o comprometimento e engajamento de todos os integrantes da organização são necessários para a formação de competências essenciais. As competências organizacionais são desenvolvidas conforme se aprimora a habilidade de usar os recursos tangíveis e intangíveis da organização para alcançar um padrão de desempenho satisfatório para atingir determinado objetivo.

Em função das características e complexidade da competitividade na sociedade contemporânea, é preciso, além de estar atento à evolução das necessidades de treinamento dos clientes, manter também a confidencialidade dos produtos dentro da rede, ou seja, através do pagamento de royalties pelo uso dos jogos, implicando em uma relação de confiança entre os membros e a rede.

Com a constante circulação de informações na rede, manter sua confidencialidade por meio de mecanismos contratuais e legais é uma das formas que podem ser utilizadas para evitar possíveis vazamentos e, consequentemente, garantindo a vantagem competitiva da organização (EASTERBY-SMITH, LYLES; TSANG, 2008, 2008; TRKMAN; DE SOUZA, 2012;).

A interconexão entre objetivos comuns e ações colaborativas se relaciona a altos níveis de coalizão, conectando-se a altos níveis de poder dos agentes quanto ao seu status conferido pela rede (PUTNAM, 1996; ROWLEY, 1997).

Os princípios do modelo andragógico potencializa o uso cada vez maior da tecnologia no processo de treinamento empresarial, visto que o futuro se apresenta mais e mais associado ao desenvolvimento de novas tecnologias em todos os campos do saber. Nessa linha de raciocínio, a tecnologia não deve ser concebida apenas como simples ferramenta de produção ou de informação, mas sim, em seu aspecto de proporcionar maior eficiência e eficácia na realização dos diferentes tipos de trabalho, o que provoca enormes impactos nos controles administrativos empresariais e também nos aspectos pessoais (CHIAVENATO, 2009).

\section{- Fator 6. Atualização contínua dos jogos como estratégia de crescimento}

Em relação à GC na rede para alcance de vantagem competitiva, um dos fatores mais proeminentes diz respeito à criação e o desenvolvimento de produtos da CJC que possuem, como elemento essencial, a criatividade que corresponde a uma de suas características mais marcantes, o que a difere da concorrência. Essa criatividade garante a CJC alta taxa de recompra de seus produtos e que lhe conferiu o reconhecimento pela Catalyst Global ao premiá-la pelo maior volume de vendas na América Latina, por dois anos seguidos.

Essa criatividade se reflete da seguinte forma: o produto criado por algum membro é disponibilizado a todos da rede. Em posse desse conhecimento explícito, a CJC utiliza o conhecimento tácito de seus colaboradores para realizar modificações de forma a adaptar os 
produtos à cultura local e personalizá-los de acordo com o ramo de especialidade do cliente. Esse processo se assemelha à conversão do conhecimento por internalização, proposta pela Espiral do Conhecimento de Nonaka;Takeuchi (1995).

Apesar de não ter sido mencionado nas respostas dos entrevistados, na observação dos pesquisadores foi constatado o fato da rede Catalyst Global ter sido a criadora do conceito de team-building e a CJC ser representante exclusiva da Catalyst Global no Brasil. Nos anos 2017 e 2018, a Catalyst Global alcançou o maior ticket médio da rede pela maior quantidade de vendas entre os membros das Américas. A CJC também inseriu um jogo próprio na rede que se chama Goal e que fez sucesso, especialmente, na época da última Copa do Mundo. 0 jogo possui um dos aspectos culturais mais conhecidos do Brasil que é o futebol e caracterizase por ser hands-on, "mão na massa".

Em síntese, os princípios propostos pelo Modelo andragógico (KNOWLES; HOLTON III; SWANSON, 2009) faz com que os jogos corporativos estimulem os participantes a desenvolver atitudes voltadas para a iniciativa e protagonismo como forma de se alcançar a autonomia. A experiência dos participantes proporciona insights para criação de novos jogos corporativos, cujas temáticas devem estar relacionadas com as situações vivenciadas no seu dia-a-dia. A aplicação da aprendizagem tem como principal finalidade possibilitar mudanças práticas e imediatas no comportamento dos treinandos, sendo que, o processo motivacional busca acima de tudo propiciar sentido de importância ao desempenho profissional.

Assim, no mercado de jogos corporativos, os seis fatores para o alcance de vantagem competitiva, bem como os seis princípios presentes no modelo androgógico, criam valor para o cliente. No mercado de prestação de serviços, a visão atual de interação entre organizações e cliente remetem a criação de valor gerada por meio das experiências entre empresa e clientes, o que resulta no processo de co-criação como meio para se alcançar vantagem competitiva sustentável (PRAHALAD et al., 2004).

\section{CONSIDERAÇÕES FINAIS}

Ao final dessa pesquisa é possível concluir que a aplicação da GC nas redes de relacionamento com o auxílio do modelo andragógico constituem elemento estratégico e imprescindível para as empresas de jogos corporativos alcançarem vantagem competitiva, visto que, um dos principais desafios das organizações contemporâneas está em transformar o conhecimento tácito em conhecimento explícito, portanto mais facilmente compartilhável, para a sua própria sustentabilidade.

Outro aspecto a ser destacado diz respeito ao conhecimento organizacional que, embora se volte para a inovação, também é composto por aprendizados e experiências passadas, as quais precisam ser preservadas e, para isso, é preciso considerar que, enquanto as organizações criam e compartilham conhecimento, também podem perder ou esquecer $o$ conhecimento que possuem.

Assim, gerenciar a base de conhecimento de uma organização engloba alguns processos específicos, como: extração e armazenamento de conhecimento, compartilhamento de conhecimento e inovação contínua.

Dentre os fatores determinantes para o sucesso do empreendimento dos jogos corporativos, destaca-se a criatividade na adaptação dos jogos para os diferentes públicos, o compartilhamento do conhecimento na rede como forma de atualização contínua, a incorporação de novas tecnologias educacionais para proporcionar entretenimento aos treinandos e, ao mesmo tempo, eficiência para a empresa atingir seus objetivos.

Com esse intuito, a GC constitui procedimento essencial para a formação de competências organizacionais que se caracterizam pela troca contínua de informações nas

Perspectivas em Gestão \& Conhecimento, João Pessoa, v. 10, n. 2, p. 42-66, maio/ago. 2020. 
redes de relacionamento sem as quais a criatividade e atualização dos conteúdos não seriam possíveis.

Por um lado, embora o conhecimento explícito não represente um papel tão dominante quanto o tácito no processo de criação e inovação, nos jogos de treinamento corporativos, os conhecimentos tácitos e explícitos em interatividade dinâmica, permitem que as experiências práticas sejam codificadas em conhecimento explícito para replicação. Por outro, o processo criativo e a atualização dos conteúdos nas redes dificultam para os concorrentes da CJC a imitação dos produtos comercializados pela empresa em curto espaço de tempo, o que constitui o alcance da vantagem competitiva sustentável.

A contribuição da pesquisa está principalmente em relacionar a importância da GC nos treinamentos relacionados aos jogos de treinamento corporativos, uma vez que na revisão da literatura, não foram encontradas pesquisas que relacionassem esses dois termos.

Evidentemente, essa pesquisa possui limitações. Dentre as quais, pode-se destacar a dificuldade de generalização por constituir um estudo de caso único, todavia, esse foi apenas um primeiro passo no estudo dos jogos de treinamento corporativos relacionados à GC e aprendizagem organizacional.

Para futuras pesquisas, sugerem-se análises comparativas em empresas de jogos corporativos pertencentes em redes e empresas não integradas em redes com a finalidade de extraírem-se novas proposições de pesquisa.

\section{REFERÊNCIAS}

ARGOTE, Linda; INGRAM, Paul. Knowledge transfer: A basis for competitive advantage in firms. Organizational Behavior and Human Decision Processes, v. 82, n. 1, p. 150-169, 2000. Disponível em: http://www.columbia.edu/ pi17/2893a.pdf. Acesso em 25 jul. 2020.

ARGOTE, Linda; FAHRENKOPF, Erin. Knowledge transfer in organizations: The roles of members, tasks, tools, and networks. Organizational Behavior and Human Decision Processes, v. 136, p. 146-159, 2016. Disponível em: https://www.sciencedirect.com/science/article/abs/pii/S0749597816304903. Acesso em: 25 jul 2020.

ATHERTON, Andrew; PRICE, Liz. Can experiential knowledge and localised learning in start-up policy and practice be transferred between regions? The case of the START network. Entrepreneurship and Regional Development, v. 20, n. 4, p. 367-385, 2008. Disponível em: https://www.tandfonline.com/doi/full/10.1080/08985620701872043. Acesso em: 28 jul. 2020.

BAGGIO, Rodolfo; COOPER, Chris. Knowledge transfer in a tourism destination: the effects of a network structure. The Service Industries Journal, v. 30, n. 10, p. 1757-1771, 2010. Disponível em: https://www.tandfonline.com/doi/full/10.1080/02642060903580649. Acesso em: 20 jul. 2020.

BODER, André. Collective intelligence: a keystone in knowledge management. Journal of Knowledge Management, v. 10, n. 1, p. 81-93, 2006. Disponível em: https://www.emerald.com/insight/content/doi/10.1108/13673270610650120/full/html. Acesso em: 27 jul. 2020.

BRANDALIZE, Adalberto. Jogos de empresa como ferramenta de treinamento e seleção de Executivos e Acadêmicos. Revista Eletrônica Ciências Empresarias, v. 2, n. 3, p. 31-45, 2018. 
Disponível em: http://periodicos.unifil.br/index.php/revista-empresrial/article/view/440, acesso em 26 jul. 2020.

BUKOWITZ, Wendi R.; WILLIAMS, Ruth L. Manual de Gestão do Conhecimento: ferramentas e técnicas que criam valor para a empresa. Porto Alegre: Bookman, 2002.

CARVALHO, José Ricardo. Andragogia: saberes docentes na educação de adultos. Revista Diálogos Acadêmicos, v. 5, n. 2, 2017. Disponível em: http://revista.fametro.com.br/index.php/RDA/article/view/121. Acesso em: 27 jul. 2020.

CASTELLS, Manuel. A era da informação: a sociedade em rede. Rio de Janeiro: Paz e Terra, v. 2, 1999.

CATALYST GLOBAL. Disponível em: https://www.catalystglobal.com/. Acesso em: 20 jul. 2020.

CAVALCANTI, Roberto de Albuquerque; GAYO, Maria Alice Fernandes da Silva. Andragogia na educação universitária. Revista Conceitos, n. 11, 2005. Disponível em: https://pt.slideshare.net/KARLLAUNA/aula-2-artigo-cavalcanti-e-gayo-2005-andragogia-naeducao-universitaria. Acesso em: 27 jul. 2020.

CAVUSGIL, S. Tamer; CALANTONE, Roger J.; ZHAO, Yushan. Tacit knowledge transfer and firm innovation capability. Journal of Business \& Industrial Marketing, v. 18, n. 1, p. 6-21, 2003. Disponível em: https://www.emerald.com/insight/content/doi/10.1108/08858620310458615/full/html. Acesso em: 27 jul. 2020.

CHEN, Chung-Jen; HUANG, Jing-Wen; SIAO, Yung-Chang. Knowledge management and innovativeness: The role of organizational climate and structure. International Journal of Manpower, v. 31, n. 8, p. 48-70, 2010 . Disponível em: https://www.emerald.com/insight/content/doi/10.1108/01437721011088548/full/html.

Acesso em: 27 jul. 2020.

CHIAVENATO, Idalberto. Treinamento e desenvolvimento de recursos humanos: como incrementar talentos na empresa. 7. ed. Barueri: Manole, 2009.

CONQUISTAR JOGOS CORPORATIVOS. Disponível em: https://www.conquistar.com.br/. Acesso em: 20 jul. 2020.

CRESWELL, John W. Investigação Qualitativa e Projeto de Pesquisa: escolhendo entre cinco abordagens. Porto Alegre: Penso, 2014.

DAVENPORT, Thomas. Saving IT's Soul: Human Centered Information Management. Harvard Business Review, v. 72, n. 2, p. 119-131, 1994. Disponível em: https://hbr.org/1994/03/savingits-soul-human-centered-information-management. Acesso em: 28 jul. 2020.

DE OLIVEIRA, Djalma de Pinho Rebouças. Sistemas de informações gerenciais: estratégicas, táticas, operacionais. São Paulo: Atlas, 2004.

DU PLESSIS, Marina. The role of knowledge management in innovation. Journal of Knowledge Management, v. $11, \quad$ n. 4, p. 20-29, 2007. Disponível em: 
https://www.emerald.com/insight/content/doi/10.1108/13673270710762684/full/html Acesso em: 27 jul. 2020.

EASTERBY-SMITH, Mark; LYLES, Marjorie A.; TSANG, Eric W. K. Inter-organizational knowledge transfer: Current themes and future prospects. Journal of Management Studies, v. 45, n. 4, p. 677-690, 2008. Disponível em: https://onlinelibrary.wiley.com/doi/10.1111/j.14676486.2008.00773.x. Acesso em: 27 jul. 2020.

EISENHARDT, Kathleen M. Building theories from case study research. Academy of Management Review, v. 14, n. 4, p. 532-550, 1989. Disponível em: https://journals.aom.org/doi/10.5465/amr.1989.4308385. Acesso em: 27 jul. 2020.

FORSYTH, Donelson R. Group dynamics. 3. ed. Boston, MA: Brooks/Cole, 1999.

FROGERI, Rodrigo; VASCONCELOS, Silmar FRANÇA; Janaina S.S.P; PARDINI, Daniel J.; FERREIRA, Daniela A.A. Aprendizagem organizacional, gestão do conhecimento e capacidades dinâmicas: proposta de um modelo teórico relacional. Perspectivas em Gestão \& Conhecimento, v.9, n.2, p.24-29, 2019. Disponível em https://periodicos.ufpb.br/ojs2/index.php/pgc/article/view/41397/27434. Acesso em: 26 jul. 2020.

GARDNER, Dana. Knowledge that Won't Fit in a Database - People. InfoWorld, v. 20, n. 14, p. 98, $1998 . \quad$ Disponível em: https://books.google.com.br/books?id=5IAEAAAAMBAJ\&pg=PA98\&lpg=PA98\&dq. Acesso em: 28 jul. 2020.

GIBBERT, Michael; KRAUSE, Hartmut. Practice exchange in a best practice marketplace. In: DAVENPORT, Thomas H.; PROBST, Gilbert J. B. (Eds.). Knowledge Management Case Book: Siemens Best Practices. Erlangen: Publicis Corporate Publishing, 2002. p. 89-105.

GIL, Antonio Carlos. Metodologia do ensino superior. São Paulo: Atlas, 2010.

GONZALEZ, Rodrigo Valio Dominguez; MARTINS, Manoel Fernando; TOLEDO, Jose Carlos. Managing knowledge in a service provider: a network structure-based model. Journal of Knowledge Management, v. 18, n. 3, p. 611-630, 2014. Disponível em: https://www.emerald.com/insight/content/doi/10.1108/JKM-12-2013-0502/full/html. Acesso em: 27 jul. 2020.

GRANT, Robert M. Toward a knowledge-based theory of the firm. Strategic Management Journal, v. 17, Special Issue 2, p. 109-122, 1996. Disponível em: https://onlinelibrary.wiley.com/doi/abs/10.1002/smj.4250171110. Acesso em: 27 jul. 2020.

HALAWI, Leila A.; ARONSON, Jay E.; MCCARTHY, Richard V. Resource-based view of knowledge management for competitive advantage. The Electronic Journal of Knowledge Management, $\begin{array}{llllll} & \text { v. } 3, & \text { n. } & \text { p. } & \text { 2005. Disponível em: }\end{array}$ http://www.ejkm.com/issue/download.html?idArticle=55. Acesso em: 27 jul. 2020.

HALLIN, Carina Antonia; MARNBURG, Einar. Knowledge management in the hospitality industry: a review of empirical research. Tourism Management, v. 29, n. 2, p. 366-381, 
2008. Disponível em: https://www.sciencedirect.com/science/article/pii/S026151770700043X. Acesso em: 27 jul. 2020.

HATCH, Katharine D.; MCCARTHY, Christopher J. Exploration of challenge courses' long-term effects on members of college student organizations. Journal of experiential education, v. 27, n. 3, p. 245-264, 2005.2 Disponível em: https://journals.sagepub.com/doi/abs/10.1177/105382590502700304. Acesso em: 27 jul. 2020.

$\mathrm{HCl}$ Profesional Services. Knowledge Management 10 Point Checklist, 2019. Disponível em: https://www.hci.com.au/km-checklist. Acesso em: 10 mar. 2019.

HUNG, Richard Yu Yuan; LIEN, Bella Ya-Hui; YANG, Baiyin; WU, Chi-Min; KUO, Yu-Ming. Impact of TQM and organizational learning on innovation performance in the high-tech industry. International Business Review, v. 20, n. 2, p. 213-225, 2011. Disponível em: https://www.sciencedirect.com/science/article/pii/S0969593110000855. Acesso em: 27 jul. 2020.

INKPEN, Andrew C.; TSANG, Eric W. K. Reflections on the 2015 decade award-social capital, networks, and knowledge transfer: An emergent stream of research. Academy of Management Review, v. 41, n. 4, p. 573-588, 2016. Disponível em: https://journals.aom.org/doi/abs/10.5465/amr.2016.0140. Acesso em: 27 jul. 2020.

INTEGRAÇÃO ESCOLA DE NEGÓCIOS(IEN). Disponível em: https://integracao.com.br/. Acesso em: 20 jul. 2020.

JOLINK, Mark; DANKBAAR, Ben. Creating a climate for inter-organizational networking through people management. The International Journal of Human Resource Management, v. 21, n. 9, p. 1436-1453, 2010. Disponível em: https://www.tandfonline.com/doi/full/10.1080/09585192.2010.488445. Acesso em: 27 jul. 2020.

JUNEJA, Prachi. Team building games and activities. Disponível em: https://www.managementstudyguide.com/team-building-games-activities.htm. Acesso em: 15 fev. 2019.

KHAN, Zaheer. Determinants of a successful cross-border knowledge transfer in franchise networks. Journal of Asia Business Studies, v. 10, n. 2, p. 148-163, 2016. Disponível em: https://www.emerald.com/insight/content/doi/10.1108/JABS-05-2015-0052/full/html. Acesso em: 27 jul. 2020.

KIM, Seckyoung Loretta; YUN, Seokhwa. The effect of coworker knowledge sharing on performance and its boundary conditions: An interactional perspective. Journal of Applied Psychology, v. 100, n. 2, p. 575, 2015. Disponível em: https://psycnet.apa.org/buy/201437306-001. Acesso em 28.jul.2020.

KNOWLES, Malcom S.; HOLTON III, Elwood F.; SWANSON, Richard A. Aprendizagem de resultados: uma abordagem prática para aumentar a efetividade da educação corporativa. Rio de Janeiro: Elsevier, 2009.

Perspectivas em Gestão \& Conhecimento, João Pessoa, v. 10, n. 2, p. 42-66, maio/ago. 2020. 
KORBI, Fadia Bahri; CHOUKI, Mourad. Knowledge transfer in international asymmetric alliances: the key role of translation, artifacts, and proximity. Journal of Knowledge Management, v. 21, n. 5, p.1272-1291, 2017. Disponível em: https://www.emerald.com/insight/content/doi/10.1108/JKM-11-2016-0501/full/html. Acesso em: 27 jul. 2020.

LEFEBVRE, Virginie Marie; SORENSON, Douglas; HENCHION, Maeve; GELLYNCK, Xavier. Social capital and knowledge sharing performance of learning networks. International Journal of Information Management, v. 36, p. 570-579, 2016. Disponível em: https://www.sciencedirect.com/science/article/pii/S0268401215001097. Acesso em: 27 jul. 2020.

LIAO, Chechen; CHUANG, Shu-Hui; TO, Pui-Lai. How knowledge management mediates the relationship between environment and organizational structure. Journal of business research, v. 64, n. 7, p. 728-736, 2011. Disponível: https://www.sciencedirect.com/science/article/pii/S0148296310001529. Acesso em: 27 jul. 2020.

LIN, Feng-Jyh; LIN, Yi-Hsin. The effect of network relationship on the performance of SMEs. Journal of Business Research, v. 69, n. 5, p.1780-1784, 2016. Disponível em: https://www.sciencedirect.com/science/article/pii/S0148296315004786. Acesso em: 27 jul. 2020.

LIN, Tung-Ching; CHANG, Christina Ling-Hsing; TSAI, Wen-Chin. The influences of knowledge loss and knowledge retention mechanisms on the absorptive capacity and performance of a MIS department. Management Decision, v. 54, n. 7, p. 1757-1787, 2016. Disponível em: https://www.emerald.com/insight/content/doi/10.1108/MD-02-2016-0117/full/html. Acesso em: 27 jul. 2020.

LÓPEZ-SÁEZ, Pedro; NAVAS-LÓPEZ, José Emilio; MARTÍN-DE-CASTRO, Gregorio; CRUZ-GONZÁLEZ, Jorge. External knowledge acquisition processes in knowledge-intensive clusters. Journal of Knowledge Management, v. 14, n. 5, p. 690-707, 2010. Disponível em: https://www.emerald.com/insight/content/doi/10.1108/13673271011074845/full/html.

Acesso em: 27 jul. 2020.

MANGAL, Shubhra. K; MANGAL, Uma. Essentials of educational technology. New Delhi: PHI Learning, 2009.

MARCONI, Marina de Andrade; LAKATOS, Eva Maria. Fundamentos de metodologia científica. 8. ed. São Paulo: Atlas, 2017.

MCGRATH, Joseph E.; ARGOTE, Linda. Group processes in organizational contexts. In: HOGG, Michael A.; TINDALE, Scott. Blackwell handbook of social psychology: Group processes. Hoboken: Blackwell Publishing, 2001. p. 603-627.

MELLO, Selma Ferraz Motta. Comunicação e organizações na sociedade em rede: novas tensões, mediações e paradigmas. 2010. Dissertação (Mestrado em Interfaces Sociais da Comunicação) - Escola de Comunicações e Artes, Universidade de São Paulo, São Paulo, 2010. Acesso em: 16 jun. 2019.

Perspectivas em Gestão \& Conhecimento, João Pessoa, v. 10, n. 2, p. 42-66, maio/ago. 2020. 
MENEZES, Katia Costa de; JOHANN, Juliana; VALENTIM, Patrícia Passeri; SCOTT, Patrícia. Gestão do conhecimento nas organizações: uma aprendizagem em rede colaborativa. Perspectivas em Gestão \& Conhecimento, v. 7, p. 145-159, 2017. Disponível em: https://periodicos.ufpb.br/ojs2/index.php/pgc/article/view/33294. Acesso em: 27 jul. 2020.

MESO, Peter; SMITH, Robert. A resource-based view of organizational knowledge management systems. Journal of Knowledge Management, v. 4, n. 3, p. 224-234, 2000. Disponível em: https://www.emerald.com/insight/content/doi/10.1108/13673270010350020/full/html.

Acesso em: 27 jul. 2020.

NIEVES, Julia; QUINTANA, Agustín; OSORIO, Javier. Knowledge-based resources and innovation in the hotel industry. International Journal of Hospitality Management, v. 38, p. 65-73, 2014. Disponível em: https://www.sciencedirect.com/science/article/pii/S0278431914000097. Acesso em: 27 jul. 2020.

NONAKA, I.; KONNO, N. The concept of "Ba": building a foundation for knowledge creation. California Management Review, v.40, n. 3, 1998.

NONAKA, Ikujiro; TAKEUCHI, Hirotaka. The knowledge-creating company. Oxford: Oxford University Press, 1995.

NONAKA, Ikujiro; TAKEUCHI, Hirotaka. Criação do Conhecimento na Empresa: como as empresas geram a dinâmica da inovação. Rio de Janeiro: Campus, 1997.

NONAKA, Ikujiro; TAKEUCHI, Hirotaka. Gestão do Conhecimento. São Paulo: Bookman, 2008.

OLIVEIRA JUNIOR, Moacir de Miranda. Transferência de conhecimento e o papel das subsidiárias em corporações multinacionais. In: FLEURY, Afonso; FLEURY, Maria Tereza Leme (Orgs.). Internacionalização e os países emergentes. São Paulo: Atlas, 2007. p. 216-237.

PIES, Marcelino Pedrinho; BAGGIO, Daniel Knebel; ROMEIRO, Maria do Carmo. Participação dos associados: um pilar estratégico de governança do cooperativismo. Revista de Administração IMED, v. 6, n. 2, p. 221-236, 2017. Disponível em: https://seer.imed.edu.br/index.php/raimed/article/view/1579. Acesso em: 27 jul. 2020.

POLANYI, Michael. A dimensão tácita. Inovatec: Portugal, 2010.

PRAHALAD, Coimbatore Krishnarao; HAMEL, Gary. The core competence of the corporation. Harvard Business Review, p. 79-91, 1990. Disponível em: https://hbr.org/1990/05/the-core-competence-of-the-corporation. Acesso em: 28 jul. 2020.

PRAHALAD, Coimbatore Krishnarao. et al. 0 futuro da competição: como desenvolver diferenciais inovadores em parceria com os clientes. Elsevier, 2004.

PRINCE, Michael. Does active learning work? A review of the research. Journal of Engineering Education, v. 93, n. 3, p. 223-231, 2004. Disponível em: https://onlinelibrary.wiley.com/doi/abs/10.1002/j.2168-9830.2004.tb00809.x. Acesso em: 27 jul. 2020.

Perspectivas em Gestão \& Conhecimento, João Pessoa, v. 10, n. 2, p. 42-66, maio/ago. 2020. 
PROVAN, Keith G.; KENIS, Patrick. Modes of network governance: Structure, management, and effectiveness. Journal of Public Administration Research and Theory, v. 18, n. 2, p. 229-252, 2008. Disponível em: https://academic.oup.com/ipart/article/18/2/229/935895. Acesso em: 27 jul. 2020.

PUTNAM, Robert D. Comunidade e democracia: a experiência da Itália moderna. Rio de Janeiro: Editora Fundação Getúlio Vargas, 1996.

RIBEIRO, Jurema Suely de Araújo Nery; CALIJORNE, Marco Antônio Soares; JURZA, Paulo Henrique; ZIVIANI, Fabricio; NEVES, Jorge Tadeu de Ramos. Gestão do conhecimento e desempenho organizacional: Integração dinâmica entre competências e recursos. Perspectivas em Gestão \& Conhecimento, v. 7, p. 4-17, 2017. Disponível em: https://periodicos.ufpb.br/ojs2/index.php/pgc/article/view/32936. Acesso em: 27 jul. 2020.

ROWLEY, Timothy . Moving beyond dyadic ties: A network theory of stakeholder influences. Academy of Management Review, v. 22, n. 4, p. 887-910, 1997. Disponível em: https://journals.aom.org/doi/abs/10.5465/amr.1997.9711022107. Acesso em: 27 jul. 2020.

RUAS, Roberto, ANTONELLO, Claudia; BOFF, Luiz Henrique. Os Novos Horizontes da Gestão: aprendizagem organizacional e competências. Porto Alegre: Bookman, 2005.

SÁNCHEZ, José Ángel López; VIJANDE, María Leticia Santos; GUTIÉRREZ, Juan Antonio Trespalacios. Aprendizaje organizativo y creación de valor en las relaciones fabricantedistribuidor. Cuadernos de Economía y Dirección de la Empresa, n. 42, p. 35-74, 2010. Disponivel em: https://www.sciencedirect.com/science/article/pii/S1138575810700037. Acesso em: 27 jul. 2020.

SCHNEIDER, Thomas; SACHS, Sybille. The impact of stakeholder identities on value creation in issue-based stakeholder networks. Journal of Business Ethics, v. 144, n. 1, p. 41-57, 2017. Disponível em https://psycnet.apa.org/record/2015-41804-001. Acesso em 28 jul. 2020.

SEVERINO, Antonio Joaquim. Metodologia do trabalho científico. 23. ed. rev. atual. São Paulo: Cortez, 2007.

SHAW, Gareth; WILLIAMS, Allan. Knowledge transfer and management in tourism organisations: An emerging research agenda. Tourism Management, v. 30, n. 3, p. 325-335, 2009. Disponível em: https://www.sciencedirect.com/science/article/pii/S0261517708000836. Acesso em: 27 jul. 2020.

SILVA, Natacha Bertoia; FLEURY, Maria Tereza Leme. Estratégias de transferência de conhecimento em multinacionais brasileiras: estudo comparativo entre as subsidiárias adquiridas e as greenfield. Internext, v. 7, n. 1, p. 1-33, 2012. Disponível em: https://internext.espm.br/internext/article/view/130. Acesso em: 27 jul. 2020.

SILVA, Rosinda Angela da; FRANCO, Paulo Roberto. Jogos de empresa: fundamentos para competir. Curitiba: InterSaberes, 2018.

SILVER, Christy A. Where Technology and Knowledge Meet. The Journal of Business Strategy, v. $21, \quad$ n. $6, \quad$ p. 28-33, 2000 Disponível em: 
https://www.emerald.com/insight/content/doi/10.1108/eb040127/full/html. Acesso em: 27 jul. 2020.

SROKA, Włodzimierz; CYGLER, Joanna; GAJDZIK, Bożena. Knowledge transfer in networks-the case of steel enterprises in Poland. Metalurgija, v. 53, n. 1, p. 101-104, 2014. Disponível em: https://hrcak.srce.hr/104386. Acesso em: 27 jul. 2020.

STRAUHS, F.; DO, R. Gestão do Conhecimento nas organizações. Curitiba: Aymará Educação, 2012.

TORUGSA, Nuttaneeya (Ann); O'DONOHUE, Wayne. Progress in innovation and knowledge management research: From incremental to transformative innovation. Journal of Business Research, v. 69, p. 1610-1614, 2016. Disponível em: https://www.sciencedirect.com/science/article/pii/s014829631500449X. Acesso em: 27 jul. 2020.

TRKMAN, Peter; DE SOUZA, Kevin C. Knowledge risks in organizational networks: An exploratory framework. The Journal of Strategic Information Systems, v. 21, n. 1, p. 1-17, 2012. Disponível em: https://www.sciencedirect.com/science/article/pii/S0963868711000552. Acesso em: 27 jul. 2020.

WAGNER, Richard J.; CAMPBELL, John. Outdoor-based experiential training: Improving transfer of training using virtual reality. Journal of Management Development, v. 13, n. 7, p. 4-11, 1994.

https://www.emerald.com/insight/content/doi/10.1108/02621719410063350/full/html.

Acesso em: 27 jul. 2020.

WHITE, Gareth R. T.; CICMIL, Svetlana. Knowledge acquisition through process mapping: Factors affecting the performance of work-based activity. International Journal of Productivity and Performance Management, v. 65, n. 3, p. 302-323, 2016. Disponível em: https://www.emerald.com/insight/content/doi/10.1108/IJPPM-01-2014-0007/full/html.

Acesso em: 27 jul. 2020.

WONG, Kuan Yew; TAN, Li Pin; LEE, Cheng Sheng; WONG, Wai Peng. Knowledge management performance measurement: measures, approaches, trends and future directions. Information Development [S.I], p. $1-9,2013 . \quad$ Disponível em: https://journals.sagepub.com/doi/abs/10.1177/0266666913513278. Acesso em: 27 jul. 2020.

WILLIAMS, Scott D.; GRAHAM, T. Scott; BAKER, Bud. Evaluating outdoor experiential training for leadership and team building. Journal of Management Development, v. 22, n. 1, p. 45-59, 2002. Disponível em: https://www.emerald.com/insight/content/doi/10.1108/02621710310454851/full/html. Acesso em: 27 jul. 2020.

YIN, Robert K. Estudo de caso: planejamento e métodos. Porto Alegre: Bookman, 2015.

Artigo recebido em 15/09/2019 e aceito para publicação em 31/07/2020 